\title{
OPEN Retraction Note: Contrasting the complexity of the climate of the past 122,000 years and recent 2000 years
}

\section{Zhi-Gang Shao}

Retraction of: Scientific Reports https://doi.org/10.1038/s41598-017-04584-x, published online 23 June 2017

The Editors have retracted this article.

After publication it was brought to the Editors' attention [1] that it is not correct to compare values of sample entropy that were obtained from time series having vastly different lengths and sampling times, as was done in this study. The increased likelihood for nonstationarity in the longer series as well as different sampling times both significantly affect the probability of the occurrence of patterns in the data, and thus lead to inherently irrelevant comparisons of obtained sample entropy values. This means that the observed differences in sample entropy between the two time series in this study cannot be attributed to actual changes in climatic complexity. The Editors therefore no longer have confidence in the conclusions of this article.

Zhi-Gang Shao disagrees with the retraction.

\section{Reference}

1. Delgado Bonal, A. On the use of complexity algorithms: a cautionary lesson from climate research. Sci Rep 10, 5092, https://doi. org/10.1038/s41598-020-61731-7 (2020).

(c) (i) Open Access This article is licensed under a Creative Commons Attribution 4.0 International cc) License, which permits use, sharing, adaptation, distribution and reproduction in any medium or format, as long as you give appropriate credit to the original author(s) and the source, provide a link to the Creative Commons license, and indicate if changes were made. The images or other third party material in this article are included in the article's Creative Commons license, unless indicated otherwise in a credit line to the material. If material is not included in the article's Creative Commons license and your intended use is not permitted by statutory regulation or exceeds the permitted use, you will need to obtain permission directly from the copyright holder. To view a copy of this license, visit http://creativecommons.org/licenses/by/4.0/.

(C) The Publisher 2020 